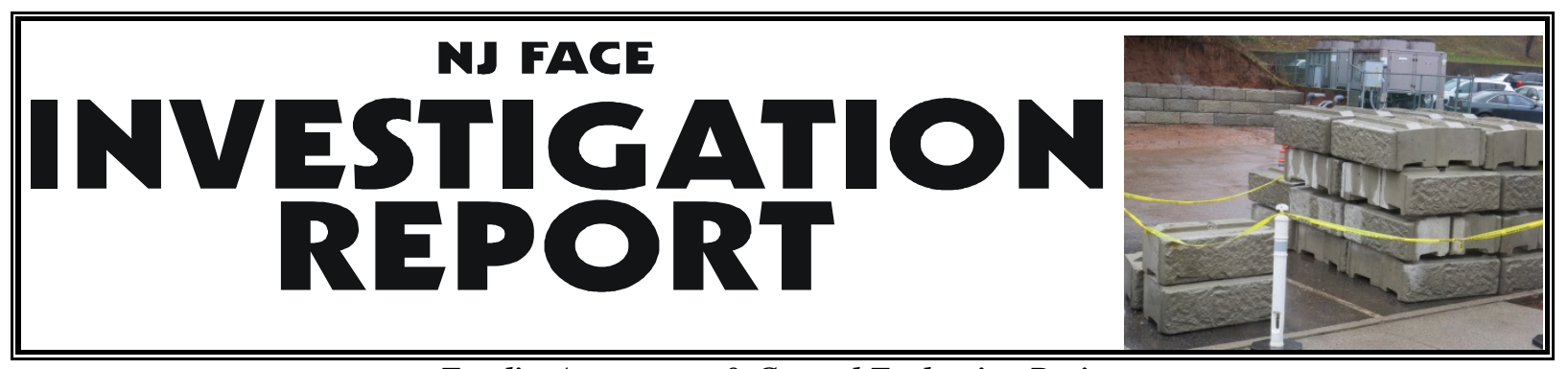

Fatality Assessment \& Control Evaluation Project

April 25, 2016

\title{
Day Laborer, First Day On The Job, Struck and Killed by Backhoe Bucket
}

A 34-year-old Hispanic day laborer was killed after he was hit in the head by the bucket of a backhoe loader. The incident occurred in the parking lot of a health care facility in northern NJ. On the day of the incident, the victim was helping two other workers build a concrete block retaining wall. It was his first day on the job. A backhoe loader was being used to transport concrete blocks from a staging pile to the wall by connecting blocks to the bucket of the backhoe with a chain. The victim was standing near the backhoe loader preparing to connect a block to the bucket when the operator, not realizing the victim was there, rotated the boom. The bucket struck the victim's head and pinned him against the stack of blocks. The victim suffered blunt force head injuries and was pronounced dead at the scene about fifteen minutes later.

Contributing Factors

- Worker standing within swing radius of backhoe loader boom

- $\quad$ No personal protective equipment

NJ FACE investigators recommend that these safety guidelines be followed to prevent similar incidents:

- A safety and health plan based on a job hazard analysis should be developed by the employer and followed where workers are assigned tasks.

- Training of all employees on job-specific tasks is extremely important, including day laborers.

- Personal protective equipment such as hard hats and high-visibility vests should always be worn when working with backhoe loaders.

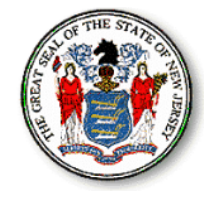

Public Health Services Branch Division of Epidemiology, Environmental and Occupational Health Occupational Health Surveillance Unit (609) 826-4984

nj.gov/health/surv/face/index.shtml 


\section{INTRODUCTION}

In winter 2014, NJ FACE staff was notified of the death of a 34-year-old Hispanic male day laborer who was killed after being struck in the head by the bucket of a backhoe loader. The incident occurred in the parking lot of a healthcare facility in northern NJ. This was the victim's first day on the job site and his first day working for this company.

A NJ FACE investigator received notification from the OSHA Area Office, and conducted a concurrent investigation. Additional information was obtained from the medical examiner's report, death certificate, police report, and the news media.

\section{INVESTIGATION}

The incident occurred on a calm, dry, winter day (approximately $40^{\circ} \mathrm{F}$ at the time of the incident, wind speed up to eight mph), with no significant precipitation recorded. The incident site was located in the parking lot of a healthcare facility (Figure 1a). The facility hired the employer to build a sidewalk and a retaining wall (Figure 1b) as part of an expansion of the parking lot. The job was to take approximately a month to complete and they had been on site about three weeks when the incident occurred. Job training was on-site, and no personal protective equipment was worn. The only piece of equipment on site was a backhoe loader, which is a tractor with a loader in the front and a small backhoe with bucket in the back (Figure 2). This particular model has a seat that swivels 180 degrees so that the operator can control the backhoe (boom and bucket) and the stabilizers from one location.

A three-person crew was originally assigned to the job site; a foreman and two other employees, all of whom were from Brazil and spoke Portuguese. After several weeks, the foreman had to leave to go back to Brazil and left one of the other employees, who had been on site (and had eight years of experience with the company), as foreman and backhoe loader operator. Needing additional help, the new foreman hired a day laborer. This employee, who spoke Spanish, worked on the site for three days, and his major task was to attach and detach the chain that was used to connect the concrete blocks to the bucket of the backhoe. The chain was connected to the blocks at fixed anchor points (Figure 3). The backhoe loader operator could then lift the block and move it from the staging area to the wall. The operator lowered the block into position and a worker would help guide this process and then detach the chain. 
FIGURE 1. Incident site; a) parking lot of health care facility, b) closer view of retaining wall.

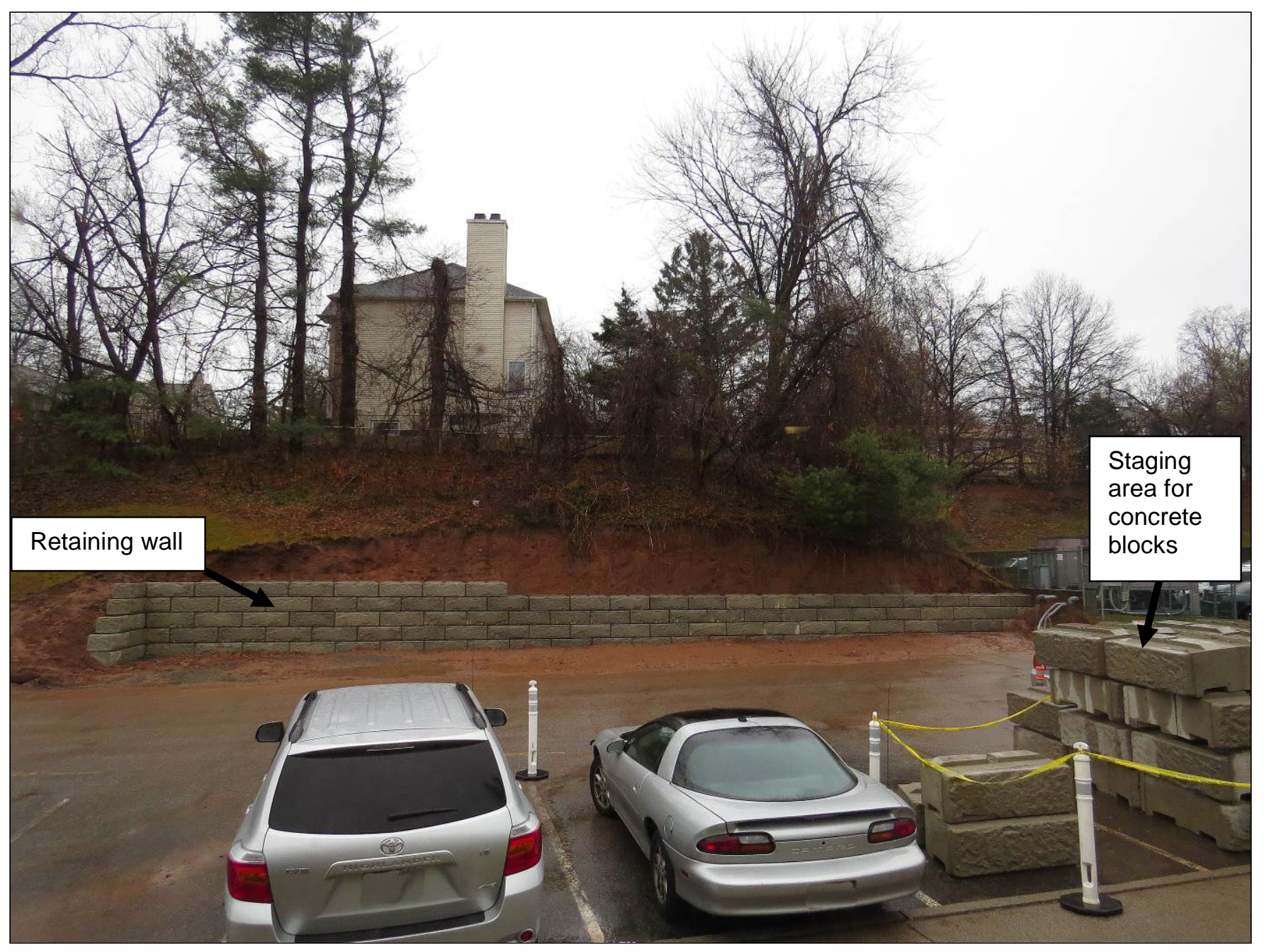

a

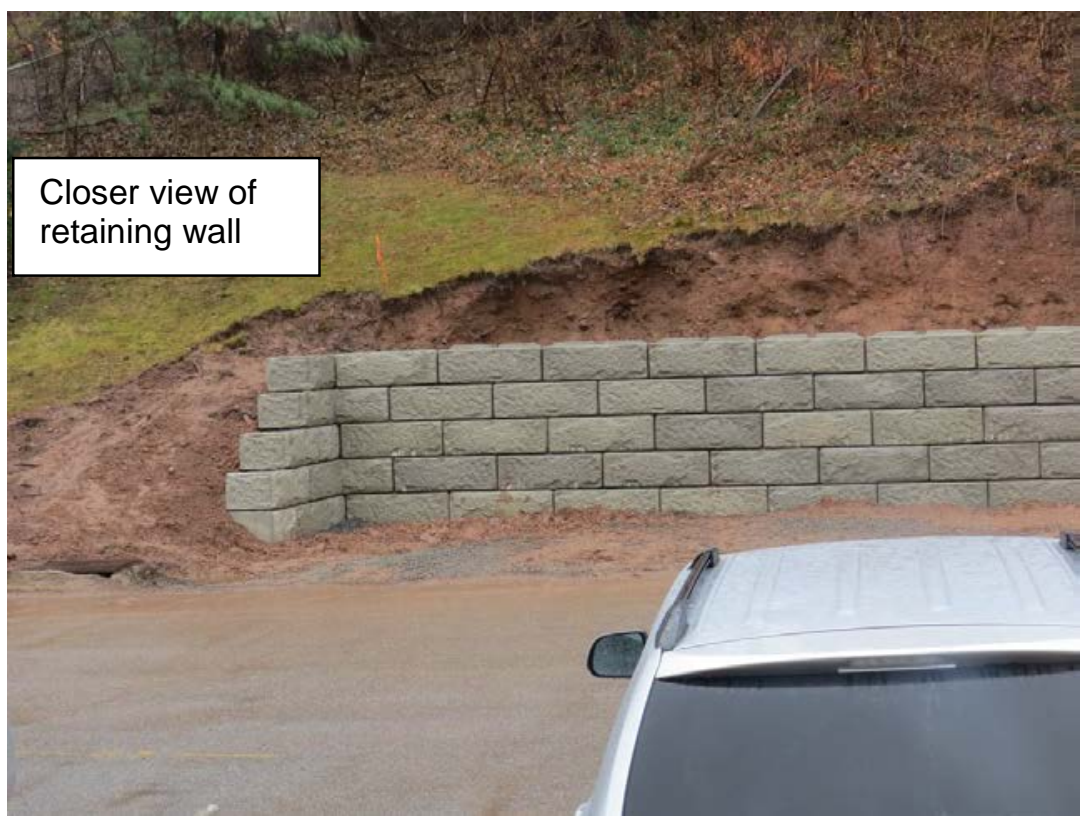

b 

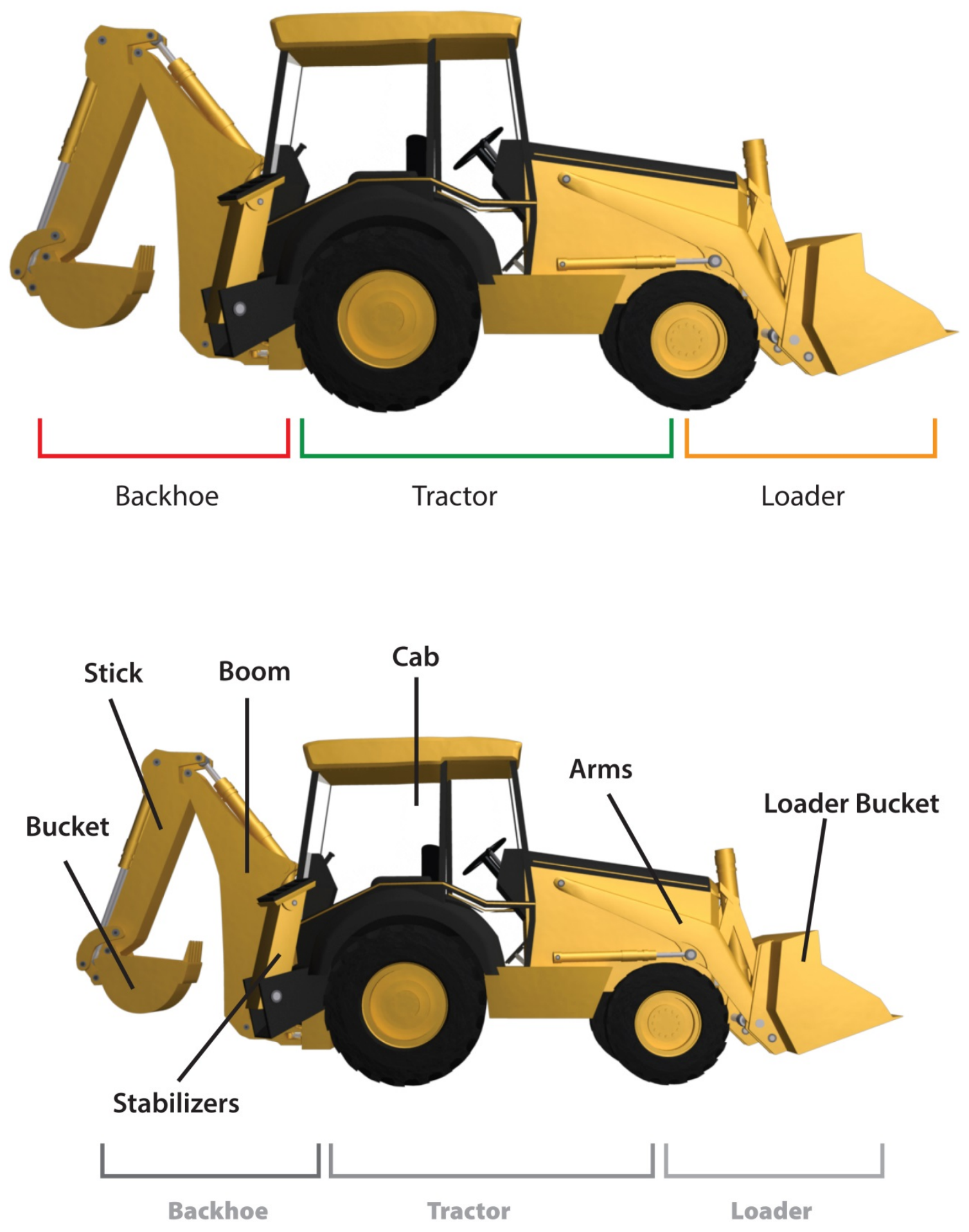

*Used with permission from HardHatTraining.com 
FIGURE 3. Concrete block with hooks to connect chain.

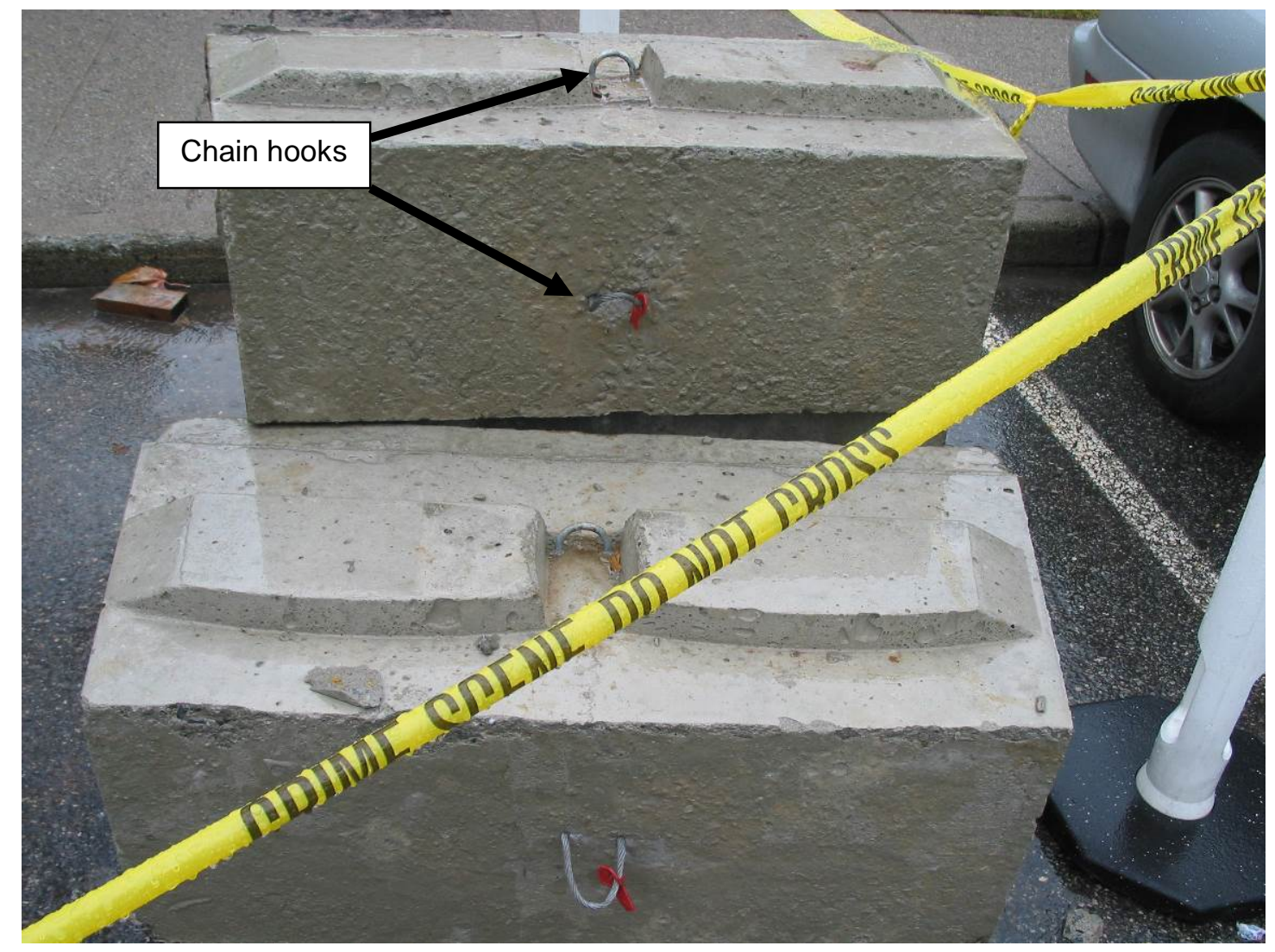

On the day of the incident, the day laborer noted above was not available to work. He notified the foreman and asked if his brother (the victim) could work instead; the foreman agreed. The foreman and another employee picked up the victim that morning at about 6:00 am, and they arrived onsite at 7:00 am. They spent the day moving blocks from the staging area to the wall in the same manner as described above. According to interviews, the victim was instructed on job tasks at the worksite in "broken Spanish" by the foreman.

The incident occurred at about 3:50 pm. The crew of three had finished setting a block on the wall, and the victim walked back to the staging area with the chain to prepare for the next block to be moved. The foreman drove the backhoe loader forward a few feet then performed a three-point turn (a "K turn") and backed in towards the stating area. He lowered the bucket to the ground, swiveled the seat 180 degrees to face the backhoe, and used the controls to lower the stabilizers to the ground. He then swung the backhoe boom to position it for the victim to attach the chain for the next block. (Figure 4). As the foreman swung the boom, it struck the victim in the head and crushed him against the pile of blocks. The victim suffered major blunt force head injuries, and was pronounced dead shortly afterwards at the site. 
FIGURE 4: Location of victim and backhoe loader at time of incident*

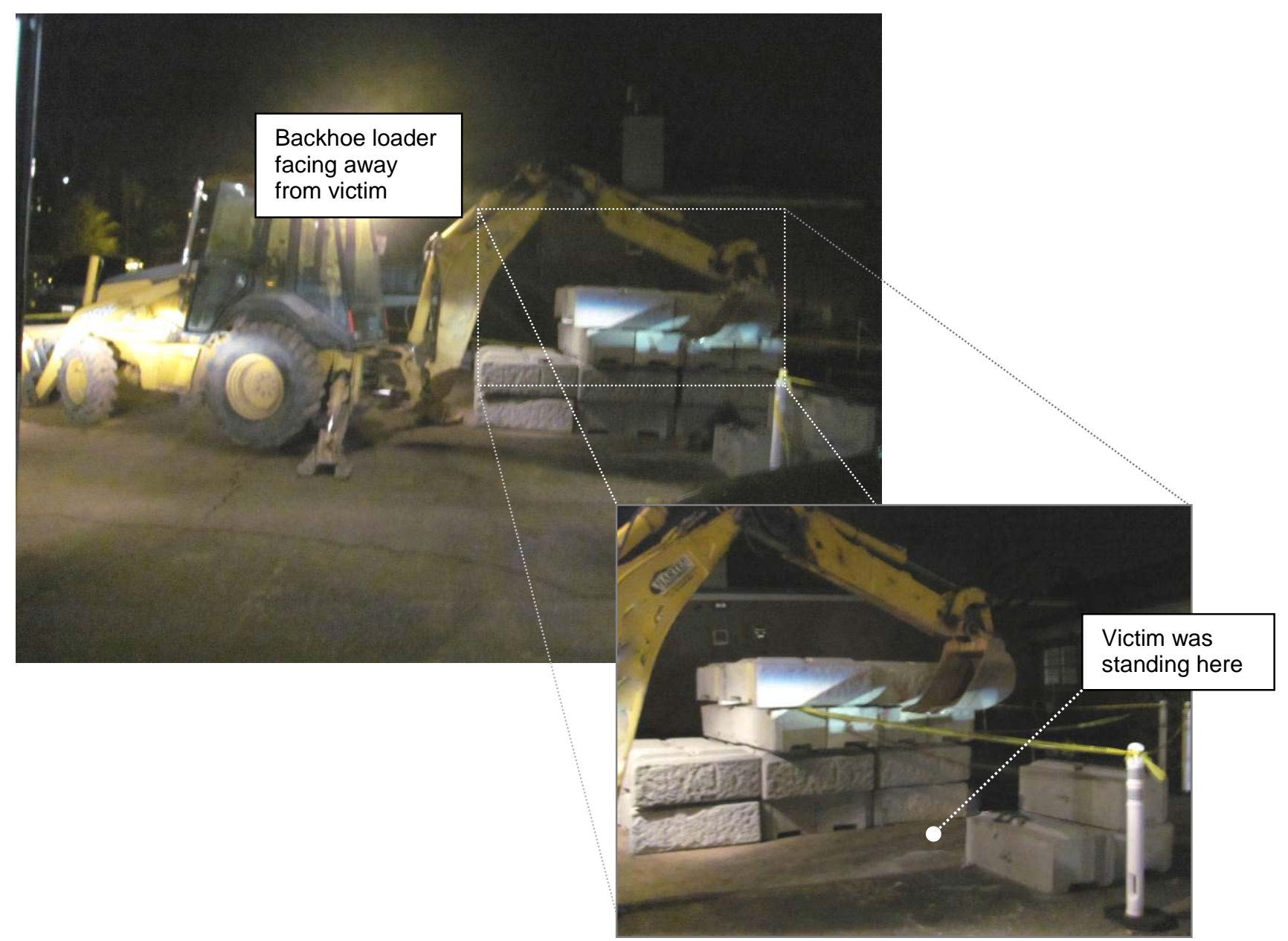

*The incident occurred during the day, but the above photos were taken later that evening. 


\section{RECOMMENDATIONS/DISCUSSIONS}

Recommendation \#1: A safety and health plan based on a job hazard analysis should be developed by the employer and followed where workers are assigned tasks.

Discussion: Employers should conduct a job hazard analysis, with the participation of employees, of all work areas and job tasks. A job hazard analysis should begin by reviewing the work activities for which the employee is responsible and the equipment that is needed. Each task is further examined for mechanical, electrical, chemical, or any other hazard the worker may encounter. A source of information on conducting a job hazard analysis can be obtained from the US Department of Labor. ${ }^{1}$

\section{Recommendation \#2: Training of all employees on job-specific tasks is extremely important, including day laborers.}

Discussion: Employees at any construction site must have adequate training on job-specific tasks. Proper training must extend to all workers, including day laborers. Language barriers and communication should also be considered during training.

Training is widely available on the basics of backhoe loader operation, load considerations, and best practices for attaching loads to the backhoe loader. Training on safe operation is also critical. The operator of a backhoe loader operator must show extreme caution and be aware vi everything in their surroundings; the backhoe needs a wide path to operate and moves much faster than might be anticipated. $^{2}$

In this case, the victim was standing within the swing radius of backhoe. The following video is a helpful tool to show all employees who work with backhoe loaders:

(https://www.youtube.com/watch?v=6YnV0Xmf6w8). Note that the workers in the video are wearing hard hats and reflective vests. NJ FACE recommends following these three guidelines at a minimum regarding employees working around/near the backhoe loader ${ }^{3}$ :

1) When the backhoe of a backhoe loader (see Figure 2) is in operation, no one should enter the full swing area of the boom. The operator's vision of this area can be limited and anyone entering may not be seen by the operator.

2) If a worker must enter the swing danger area, eye contact as well as confirmed communication (verbal/hand signal/radio/etc.) with the operator must be established (Figure 5). The worker then must wait until the operator signals that it is safe to enter this area. The operator should not move the backhoe until the worker has cleared the area. When it is necessary for the worker to remain 
in this area while the operator performs an operation, extreme care must be exercised and the worker needs to remain in the operator line of sight.

Figure 5. Stressing the importance of eye contact and communication with the operator.*

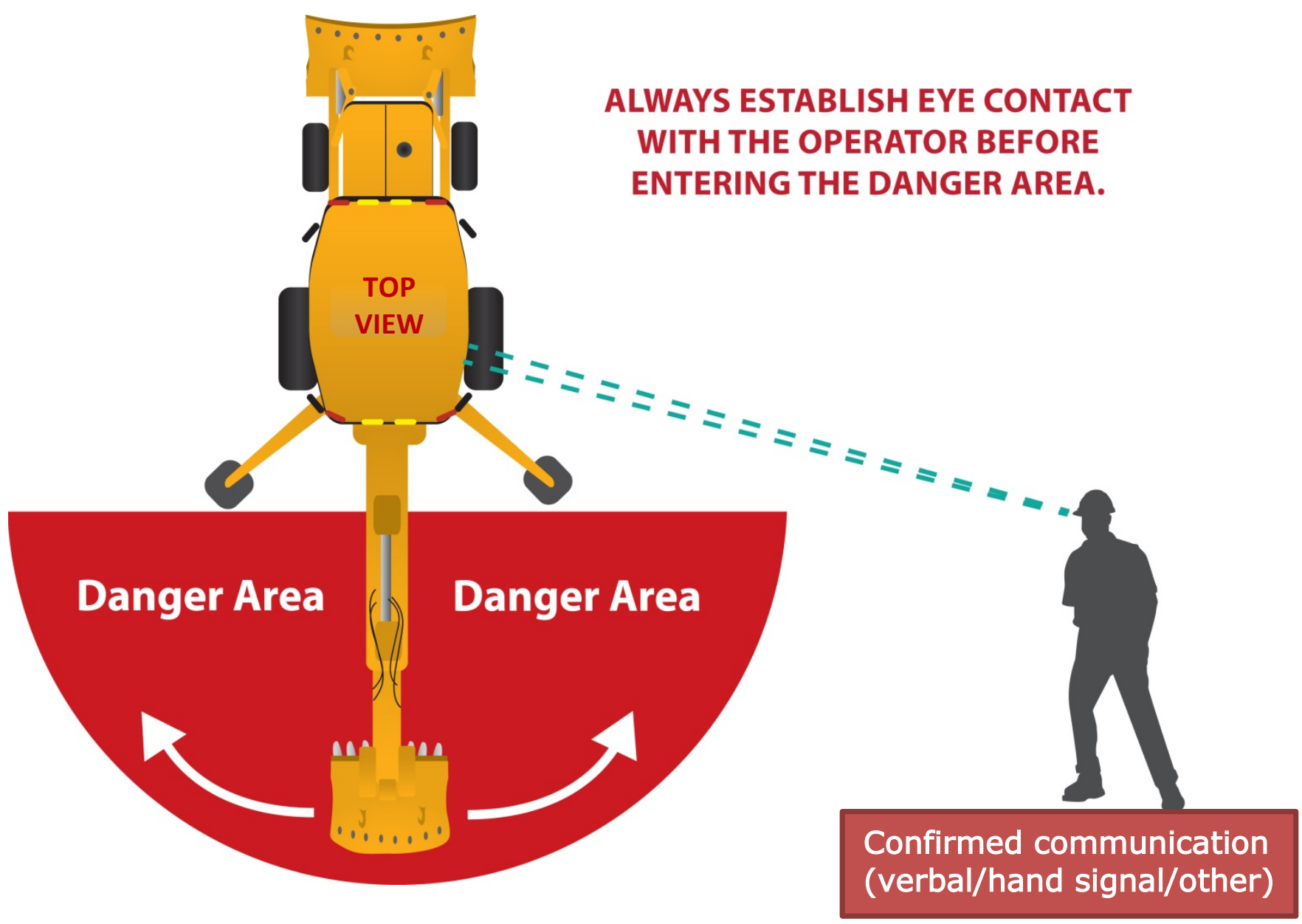

*Used/adapted with permission from HardHatTraining.com

3) When working around a backhoe loader, the worker should always work facing the machine. The machine should be considered a continuous threat to safety and thus constantly keep an eye on its movements.

Another useful training material is the NIOSH Workplace Solutions entitled, "Preventing Injuries When Working with Hydraulic Excavators and Backhoe Loaders.”4 This document presents two case studies of fatalities; provides specific recommendations to employers for best practices during site set-up; and 
lists training, hazard awareness, and injury prevention recommendations for equipment operators and other site workers.

\section{Recommendation \#3: Personal protective equipment such as hard hats and high-visibility vests} should always be worn when working with backhoe loaders.

Discussion: As per 29 CFR 1926.100(a), an employee working in an area where there is a possible danger of head injury from impact must wear head protection. ${ }^{5}$ The specific type of head protection (hard hat, helmet, etc.) must comply with American National Standards Institute (ANSI) Z89.1-2014. ${ }^{6}$ In addition, employers are required under 29 CFR 1926.100(b) to provide each employee with ANSI compliant head protection. ${ }^{7}$ In this incident, none of the workers were wearing hard hats. It is not possible to know if wearing a hard hat would have saved the life of the victim in this instance, but the impact to the head would have been reduced.

In addition, NJ FACE recommends the use of high-visibility safety vests be worn at all times when working around an operating backhoe loader. All high-visibility safety apparel should conform with ANSI/ISEA 107-2010, and are intended to make workers readily visible during daytime (and nighttime usage). ${ }^{8}$ The use of high-visibility safety apparel allows equipment operators to see workers distinctly, reducing the risk of worker injury or fatality. ${ }^{9}$ 


\section{APPENDIX}

\section{RECOMMENDED RESOURCES}

It is essential that employers obtain accurate information on health, safety, and applicable OSHA standards. NJ FACE recommends the following sources of information which can help both employers and employees:

\section{U.S. Department of Labor, Occupational Safety \& Health Administration (OSHA)}

Federal OSHA can provide information on safety and health standards on request. OSHA has several offices in New Jersey that cover the following counties:

急 Hunterdon, Middlesex, Somerset, Union, and Warren counties. $.732-750-3270$

Essex, Hudson, Morris, and Sussex counties $.973-263-1003$

Bergen and Passaic counties. 201-288-1700

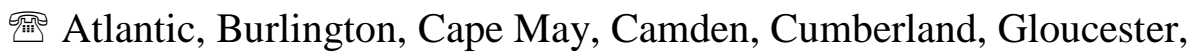

Mercer, Monmouth, Ocean, and Salem counties. 856-757-5181

Web site: $\underline{w w w . o s h a . g o v}$

\section{New Jersey Public Employees Occupational Safety and Health (PEOSH) Program}

The PEOSH Act covers all NJ state, county, and municipal employees. Two state departments administer the Act: the NJ Department of Labor and Workforce Development (NJDLWD), which investigates safety hazards, and the NJ Department of Health (NJDOH), which investigates health hazards. PEOSH has information that may also benefit private employers.

NJDLWD, Office of Public Employees Safety

㥜Telephone: 609-633-3896

Web site: www.nj.gov/labor/lsse/lspeosh.html

NJDOH, Public Employees Occupational Safety \& Health Program

留 Telephone: 609-984-1863

Web site: $\underline{w w w . n j . g o v / h e a l t h / p e o s h}$

On-site Consultation for Public Employers

绝Telephone: 609-984-1863 (health) or 609-633-2587 (safety)

Web site: www.state.nj.us/health/eoh/peoshweb/peoshcon.htm

New Jersey Department of Labor and Workforce Development, Occupational Safety and Health On-Site Consultation Program

This program provides free advice to private businesses on improving safety and health in the workplace 
and complying with OSHA standards.

霸Telephone: 609-984-0785

Web site: $\underline{w w w . n j . g o v / l a b o r / l s s e / l s o n s i t e . h t m l}$

\section{New Jersey State Safety Council}

The New Jersey State Safety Council provides a variety of courses on work-related safety. There is a charge for the seminars.

第Telephone: 908-272-7712.

Web site: $w$ ww.njsafety.org

\section{Internet Resources}

Other useful Internet sites for occupational safety and health information:

- $\mathrm{CDC} / \mathrm{NIOSH}-\underline{w w w . c d c . g o v / n i o s h}$

- USDOL Employment Laws Assistance for Workers and Small Businesses - $\underline{w w w . d o l . g o v / e l a w s}$

- National Safety Council - www.nsc.org

- NJDOH FACE reports - www.nj.gov/health/surv/face/index.shtml

- $\mathrm{CDC} / \mathrm{NIOSH}$ FACE - www.cdc.gov/niosh/face/faceweb.html

- OSHA - www.osha.gov

- ANSI - www.ansi.org

\section{REFERENCES}

1. Job Hazard Analysis. US Department of Labor Publication \# OSHA-3071, 1998 (revised). USDOL, OSHA Publications, PO Box 37535, Washington DC 20013-7535

2. 29 CFR 1926.100(a); Personal Protective and Life Saving Equipment-general; Head Protection.

3. Associated Training Services. The Backhoe. Available at: https://heavyequipmentschool.com/index.php/the-backhoe/. Accessed March 1, 2016.

4. 29 CFR 1926.100(b)(1); Personal Protective and Life Saving Equipment-general; Criteria for head protection.

5. American National Standards Institute (ANSI) Z89.1-2014; American National Standard for Industrial Head Protection.

6. The National Work Zone Safety Clearinghouse. High Visibility Apparel in Work Zones. Available at: https://www.workzonesafety.org/fhwa_wz_grant/atssa/atssa_high_visibility_pocket_guide\#s5. Accessed February 28, 2016.

7. American National Standards Institute (ANSI); 107-2010; American National Standard for High-Visibility Safety Apparel.

8. OSHA Campus Loader Backhoe Student Manual. Developed by HardHatTraining.com. Available at: 
http://www.oshacampus.com/PDF/Loader_Backhoe/Loader_Backhoe_Student_Manual.pdf . Accessed December 28, 2015. Pg 17-18.

9. NIOSH Workplace Solutions. Preventing Injuries When Working with Hydraulic Excavators and Backhoe Loaders. DHHS (NIOSH) Publication No. 2004-107. Available at: http://www.cdc.gov/niosh/docs/wp-solutions/2004-107/pdfs/2004-107.pdf Accessed January 13, 2016. Pg 1-4. 


\section{Fatality Assessment and Control Evaluation (FACE) Project \\ Investigation \# 14-NJ-74}

This report was prepared by staff members of the New Jersey Department of Health's Occupational Health Surveillance Unit. The goal of FACE is to prevent fatal work-related injuries by studying the work environment, the worker, the task, the tools the worker was using, the energy exchange resulting in the fatal injury, and the role of management in controlling how these factors interact. FACE gathers information from multiple sources that may include interviews of employers, workers, and other investigators; examination of the fatality site and related equipment; and reviewing OSHA, police, and medical examiner reports, employer safety procedures, and training plans. The FACE program does not determine fault or place blame on employers or individual workers. Findings are summarized in narrative investigation reports that include recommendations for preventing similar events. All names and other identifiers are removed from FACE reports and other data to protect the confidentiality of those who participate in the program.

NIOSH-funded state-based FACE Programs include: California, Iowa, Kentucky, Massachusetts, Michigan, New Jersey, New York, Oregon, and Washington. Please visit the NJ FACE Web site at www.nj.gov/health/surv/face/index.shtml or the CDC/NIOSH FACE Web site at www.cdc.gov/niosh/face/faceweb.html for more information.

The NJ FACE Project is supported by the Centers for Disease Control and Prevention (CDC). The contents of this report are solely the responsibility of the authors and do not necessarily represent the official views of the CDC.

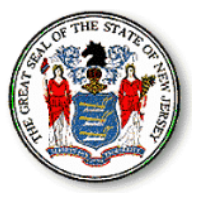

Public Health Services Branch Division of Epidemiology, Environmental and Occupational Health Occupational Health Surveillance Unit (609) 826-4984 nj.gov/health/surv/face/index.shtml 